\title{
Racismo e mídia
}

\author{
Harrison da Rocha ${ }^{1}$
}

\section{Resumo}

As culturas nacionais são compostas não apenas de instituições culturais, mas também de símbolos e representações, e o discurso é o instrumento de construção/reconstrução/manutenção de sentidos que influencia e organiza tanto nossas ações quanto a concepção que temos de nós mesmos. Nesse sentido, o discurso da mídia exerce papel preponderante na formação de consciências e, principalmente, de identidades. Mas qual é a relação entre mídia e ideologia? Este trabalho tem o objetivo de apresentar a relação entre o discurso midiático, por meio de análise de textos publicados, e a ideologia, notadamente em relação às minorias étnicas, $\mathrm{o}$ negro brasileiro. Para responder ao questionamento, recorremos aos pressupostos teóricos e à metodologia crítica da Análise de Discurso Crítica, Fairclough (2001), e, interdisciplinarmente, a Giddens (1997), a Hall (2000), a Thompson (2000), a Egleton (1997) e a van Dijk (1997). Após análise do corpus, chegou-se à conclusão de que, ao se publicarem as matérias, há todo um crivo ideológico. A maioria dos produtores de texto, na mídia, faz parte de culturas - políticas e ideológicas - diferentes das que pertencem às minorias étnicas. Nossa mídia, ao seguir o paradigma perverso, acumula antigas manifestações do imaginário racista: inferioridade intelectual do negro, perpetuação, por incapacidade congênita, de condição servil, animalização e transposição de relação de dominação.

Palavras-chave: Linguística. Análise Crítica do Discurso. Mídia. Racismo.

\footnotetext{
${ }^{1}$ Mestre e doutorando em Linguística pela Universidade de Brasília (UnB). Especialista em Língua Portuguesa pela UnB. Coordenador dos cursos de Especialização em Língua Portuguesa do UniCEUB. Professor de Língua Portuguesa e Linguística da mesma instituição. Atualmente desenvolve pesquisas nas áreas de Análise de Discurso Crítica, Multimodalidade, Letramento e Revisão de Textos. Autor de artigos científicos e livros nessas áreas.rocha123@gmail.com.
} 


\section{Introdução}

Autores como Giddens (1997, 2001), Hall (2000) e Hall \& Woodward (2000) têm escrito muito sobre a questão da identidade, mas o que é identidade? Para Woodward, identidade é o que se é. Mas é fácil ser o que se é com todas as diferenças, com todas as ideologias subjacentes a tudo isso?

Muitos autores afirmam que estamos vivendo uma crise de identidade e o que está provocando isso são: a globalização, a migração, a homogeneidade cultural, o passado com o presente, o local e o global. Hall (2000) adota este último, em uma referência dialética. No local, afirma que as identidades nacionais não são coisas com as quais nascemos, mas são formadas e transformadas no interior da representação simbólica.

Segundo o mesmo autor, as culturas nacionais são compostas não apenas de instituições culturais, mas também de símbolos e representações, e o discurso é o instrumento de construção de sentidos que influencia e organiza tanto nossas ações quanto a concepção que temos de nós mesmos.

Com a compressão do espaço-tempo, influenciada pelo fenômeno da globalização, o discurso da mídia tornou-se peça fundamental, pois a transmissão de um acontecimento distante é passada para todas as partes do globo, havendo o que se chama de intromissão de acontecimentos distantes nas consciências locais.

As estruturas sociais em termos locais - instituições privadas e estatais recebem muita influência da mídia. Sua importância é tão grande que suplanta o sistema educacional propriamente dito.

Qual é a relação entre mídia e ideologia, principalmente na publicação de temas sobre minorias étnicas, o negro? Como é processada a escolha? Por trás de tudo isso, existe o processo ideológico, pois quem escreve, seleciona e publica matérias geralmente é branco e faz parte de classe social média alta. E como está construída a identidade do negro na consciência de quem faz a escolha da notícia Como eles reconstroem essa identidade na mente de quem lê as matérias? 
Responder a esses questionamentos é o objetivo deste trabalho. Para tanto, necessita-se de pressupostos teóricos. Primeiro, busca-se um conceito de ideologia que nos dê suporte entre discurso e estrutura social. Temos de entender o fenômeno da identidade, restringindo para o conceito local - o negro na nossa sociedade. Em seguida, estudar-se-á o discurso da mídia e o preconceito presente nela. Na última parte, de natureza prática, serão analisados linguisticamente alguns textos à luz da Análise Crítica do Discurso - ACD (FAIRCLOUGH, 2001) e interdisciplinarmente, com a Sociologia. O método de pesquisa é qualitativo a partir de uma pesquisa bibliográfica: Norman Fairclough, Stuart Hall, Kathryn Woodward, Anthony Giddens, Terry Eagleton, John B. Thompson e Edson Lopes Cardoso.

\section{$2 \mathrm{Em}$ busca de um conceito de ideologia}

Toda questão de discurso envolve questões ideológicas, por isso o conceito de ideologia torna-se útil, tendo em vista os objetivos do trabalho, que estará lidando com construção de identidade via discurso. Mas segundo Eagleton (1997), "Ninguém propôs ainda uma definição única e adequada de ideologia. Há muitos conceitos, mas nenhum é completo e todos não são compatíveis entre si, por isso torna-se tarefa impossível reuni-los em um único significado". Continuando, o autor enfatiza: "O mais produtivo seria então reunir todas as definições em alguma grande teoria global e determinar o que há de valioso em cada uma delas e o que pode ser descartado". Dada a imensidão de conceitos, teremos a liberdade de escolher aqueles que estão diretamente ligados ao discurso: Eagleton (1997), Thompson (2000) e Fairclough (2001). Antes, devemos fazer breve incursão histórica sobre o conceito de ideologia.

Foi introduzido originalmente por Destutt de Tracy, que considerava a ideologia como ciência das ideias. Contrariando esse sentido, passa a ter concepção negativa para Napoleão Bonaparte, que considerava os ideólogos franceses irrealistas e perigosos. Marx e Engels condenaram o abstracionismo, o idealismo e o perigo dos ideólogos para o poder. Segundo Marx, a ideologia é um instrumento de dominação de classes porque a dominante faz com que suas ideias passem a 
ser ideias de todos. Vejamos os três conceitos que contribuem para aproximar o discurso da ideologia.

Eagleton (1997) afirma que a ideologia é uma questão de discurso. Thompson (2000), indo além da investigação histórica, desenvolve uma formulação alternativa do conceito de ideologia. Para ele, há dois conceitos: o neutro, que tenta caracterizar fenômenos como ideologia ou ideológicos sem implicar que esses fenômenos sejam necessariamente enganadores e ilusórios ou ligados aos interesses de algum grupo em particular; o crítico, que implica que o fenômeno caracterizado como ideologia ou como ideológico é enganador, ilusório ou parcial. Ele é contra o sentido neutro, por isso está interessado pelas maneiras como as formas simbólicas se entrecruzam com as relações de poder: "Estudar a ideologia é estudar as maneiras como o sentido serve para estabelecer e sustentar relações de dominação" (THOMPSON, 2000, p. 76). Para este autor, os fenômenos ideológicos são simbólicos desde que sirvam, em circunstâncias sócio-históricas específicas, para estabelecer e sustentar as relações de dominação. Mas, de que maneira pode o sentido servir para estabelecer e sustentar relações de dominação? Prestando atenção cuidadosamente na interação entre sentido e poder nas circunstâncias concretas da vida social.

O autor ainda apresenta os valiosos modos de operação da ideologia, que indicam algumas das maneiras pelas quais podem estar ligados, em circunstâncias particulares, com estratégias de construção simbólica: legitimação: racionalização, universalização, narrativização; dissimulação: deslocamento, eufemização, tropo (sinédoque, metonímia, metáfora); unificação: estandardização, simbolização da unidade; fragmentação: diferenciação, expurgo do outro; reificação: neutralização, eternização, normalização/passivização.

Fairclough (2001) afirma que há três asserções sobre ideologia: primeiro, ela tem existência material nas práticas das instituições, que abrem caminho para investigar as práticas discursivas, formas materiais de ideologia; segundo, que a ideologia constitui os sujeitos; terceiro, que as instituições são locais e marcos delimitadores na luta de classe, que apontam para a luta no discurso e subjacente a ele como foco para uma análise de discurso orientada ideologicamente. Apresenta também o seguinte conceito de ideologia que se molda aos nossos propósitos: 
São significações/construções da realidade (o mundo físico, as relações sociais, as identidades sociais) que são construídas em várias dimensões das formas/sentidos das práticas discursivas e que contribuem para a produção, a reprodução ou a transformação das relações de dominação (FAIRCLOUGH, 2001, p. 117).

\section{Identidade}

Nesta parte do trabalho, utilizaremos duas obras de capital importância para se entender a identidade: Identidade cultural na pós-modernidade (HALL, 2000) e Identidade e diferença - a perspectiva dos estudos culturais (HALL; WOODWARD, 2000).

Antes de nos aprofundarmos nas obras citadas, devemos nos perguntar: por que o conceito de identidade é importante? Primeiro, identidade é aquilo que se é; segundo, que precisamos de conceitualizações; e, por último, a análise da identidade e da diferença deve levar em conta a relação entre cultura e significado.

Woodward e Hall (2000) fazem uma abordagem sobre a conceitualização da identidade e sua existência marcada pela diferença. Segundo Woodward, a identidade está vinculada a condições sociais e materiais. Um grupo social poderá ser simbolicamente marcado por determinados bens de consumo que possuir ou preferir e poderá, com isso, tornar-se rival ou "diferente" de outro determinado grupo.

O social e o simbólico são elementos necessários para a manutenção das identidades: a marcação simbólica é o meio pelo qual damos sentido às práticas e às relações sociais, definindo, por exemplo, quem é excluído e quem é incluído e, por meio da diferenciação social, essas classificações da diferença são vividas nas relações sociais.

Para completa conceitualização da identidade e melhor explicação do motivo pelo qual as pessoas investem nas posições que os discursos de identidade lhe oferecem, a obra aponta, ao lado do simbólico e do social, a questão do nível 
psíquico. Todos esses elementos contribuem para explicar como as identidades são formadas e mantidas.

Existe uma crise de identidade? A globalização está diretamente ligada ao processo de migração. Essa migração tem impactos tanto sobre o país de origem como o de destino, produzindo identidades plurais e também identidades contestadas em um processo caracterizado por grandes desigualdades. Essa dispersão das pessoas ao redor do globo produz identidades que são moldadas e localizadas em diferentes lugares e por diferentes lugares, podendo ser, essas novas identidades, desestabilizadas e desestabilizadoras. Hall (2000) afirma que essa crise de identidade não está apenas presente no fenômeno de migração e imigração, mas sim dentro dos próprios países, pois nenhuma nação do mundo é completamente homogênea: a maioria das nações consiste de culturas separadas que só foram unificadas pelo processo de conquista violenta, pela supressão forçada de diferença cultural; todas as nações são compostas de diferentes classes sociais, diferentes grupos étnicos e de gênero; as nações ocidentais modernas foram também os centros de impérios ou de esferas neoimperiais de influência, exercendo hegemonia cultural sobre as culturas dos colonizados. E se as nações se sentem inteiras, isso só se explica pela fantasia do "eu inteiro", de acordo com Lacan. E continua com mais argumentos: "A Europa Ocidental não tem qualquer nação que seja composta de um único povo, uma única cultura ou etnia - as nações modernas são todas híbridas” (HALL, 2000).

Isso leva à pluralização de culturas nacionais e, por consequência, de identidades nacionais. No subcapítulo “A dialética das identidades”, Hall (2000) mostra os efeitos provocados nas comunidades pelo fenômeno da migração: primeiro o de contestar os contornos estabelecidos da identidade nacional e de expor seu fechamento às pressões da diferença, da "alteridade" e da diversidade cultural; outro efeito é o alargamento do campo das identidades e uma proliferação de novas posições de identidade, juntamente com um aumento de polarização entre elas - isso pode provocar o fortalecimento de identidades locais (reação defensiva) ou, por enfraquecimento dela, o surgimento de outras, o que casa com a terceira hipótese - a produção de novas identidades. A última hipótese é o da "tradução", formação de identidade por assimilação - culturas são obrigadas a negociar com as novas culturas em que vivem, sem simplesmente serem assimiladas por elas e sem perde- 
rem completamente suas identidades, e jamais serão unificadas, pois são o produto de várias histórias e culturas interconectadas. $\mathrm{O}$ autor afirma que a tendência é à homogeneização global, pois tem seu paralelo em um poderoso revival da "etnia", algumas vezes de variedades mais híbridas ou simbólicas, mas também frequentemente das variedades exclusivas ou "essencialistas" mencionadas anteriormente.

Como a diferença é marcada em relação à identidade? Os termos que sustentam uma oposição binária (nós/eles, carnívoros/vegetarianos, hetero/homo, negro/branco) envolvem um desequilíbrio necessário de poder entre eles. A diferença pode ser construída negativamente -por meio da exclusão ou da marginalização daquelas pessoas que são definidas como "outros" ou forasteiros.

Além de serem interdependentes, identidade e diferença partilham uma importante característica: elas são o resultado de atos de criação linguística. Ou seja, elas têm de ser ativamente produzidas, pois são criaturas do mundo cultural e social. Significa dizer que elas são criadas por meio de atos de linguagem. Elas têm de ser nomeadas. É apenas por meio de atos de fala que instituímos a identidade e a diferença como tais.

Essa indeterminação fatal da linguagem decorre de uma característica fundamental do signo: ele carrega sempre não apenas o traço daquilo que ele não é, ou seja, precisamente da diferença. O processo de adiamento e diferenciação linguístico por meio do qual são produzidas está longe, entretanto, de ser simétrico. A identidade, tal como a diferença, é uma relação social. Isso significa que sua definição - discursiva e linguística - está sujeita a vetores de força, a relações de poder. Elas não são simplesmente definidas, elas são impostas. Não convivem harmoniosamente, lado a lado, em um campo sem hierarquias; elas são disputadas.

Na disputa pela identidade, está envolvida uma disputa mais ampla por outros recursos simbólicos e materiais da sociedade. A afirmação da identidade e a enunciação da diferença traduzem o desejo dos diferentes grupos sociais, assimetricamente situados, de garantir o curso privilegiado aos bens sociais. A identidade e a diferença estão, pois, em estreita conexão com relações de poder. Elas não são nunca inocentes. Podemos dizer que onde existe diferenciação - ou seja, identida- 
de e diferença - está sempre presente o poder. A diferenciação é o processo central pelo qual a identidade é produzida.

O questionamento em torno de uma crise de identidade pode estar baseado tanto nas questões levantadas acima, entre países, como em uma dicotomia bastante presente entre países específicos: "nós e eles", "negros e brancos", "homens e mulheres", que constituem marcações da diferença. Essa marcação da diferença é crucial no processo de construção das posições de identidade e essa diferença é produzida por meio de sistemas simbólicos.

\subsection{Identidade local - o negro}

No nosso contexto, como está a identidade étnica, especificamente do negro, depois de 113 anos da Abolição da Escravatura? Segundo a revista Istoé, do dia 4 de julho de 2001, "São 113 anos sem grilhões, sem as marcas da chibata". Porém, em pleno século XXI a sociedade perpetua a cultura da senzala empurrando 45\% dos brasileiros ao "mito da democracia racial" e os dados desfazem a demagogia e apontam para realidades cruas.

A desigualdade se mostra em muitas áreas. No mercado de trabalho, por exemplo, temos a prova de maior desigualdade: os negros ganham, em média, a metade do salário dos brancos. Segundo o IBGE/90, o rendimento médio nacional entre negros e brancos, em salários mínimos, é de: homem branco - 6,3, homem negro - 2,9; mulher branca - 3,6, mulher negra - 1,7. As mulheres negras ocupadas em atividades manuais perfazem um total de 79,4\%: emprego doméstico - 51\%, lavadeiras, passadeiras, cozinheiras e serventes - 28,4\%; nas demais atividades: secretárias, recepcionistas e vendedoras 7,4\%; funções administrativas, técnicas, científicas e artísticas - entre 5,3 e 10\%. A diferença é fruto da discriminação no mercado de trabalho e nesse campo não houve nenhum avanço. E isso implica miséria.

Como a pobreza é gritante e historicamente construída, a imagem de que os negros são incompetentes, e por isso pobres, maqueia a questão racial. Vejam-se esses dados: 68,85\% dos indigentes são negros; $63,63 \%$ dos pobres são negros. 
Segundo publicação do Ministério do Trabalho e Emprego - MTE (BRASIL, 1998), um erro comum no enfrentamento da temática da discriminação, observado inclusive no texto constitucional, é a confusão entre os termos racismo, gênero, estereótipo, preconceito e discriminação. Tal descuido não teria maiores consequências se se tratasse apenas de mera confusão terminológica. Ocorre que a definição e a compreensão de cada um desses termos são essenciais para que saibamos identificar e combater as variadas formas de discriminação ideológica que defendem a ideia de hierarquia entre as pessoas. "Racismo é uma ideologia que postula a existência de hierarquia entre grupos humanos”. Segundo essa noção de ideologia, utilizada pela publicação, diferenças aparentes (cabelo, epiderme) e culturais entre povos determinariam também diferentes níveis de inteligência e de qualidades morais. É bom lembrar que teorias como essa nasceram a partir do momento em que os europeus saíram em busca da dominação de povos e terras "diferentes".

Poderíamos encerrar esta seção citando trecho de Eagleton (1997):

Um racista é, em geral, alguém dominado pelo medo, pelo ódio e pela insegurança, e não uma pessoa que, imparcialmente, chegou a certos juízos intelectuais sobre outras raças, e mesmo que os seus sentimentos sejam motivados por tais juízos, é provável que estejam profundamente entrelaçados a estes; e esses juízos - de que determinadas raças são inferiores a outras, por exemplo, são manifestamente falsas (EAGLETON, 1997, p. 32).

\section{0 discurso da mídia}

Para Giddens (1997), uma das coisas que explicam o caráter dinâmico da vida social moderna é a separação do tempo e do espaço:

[...] um mundo que tem um sistema de datação universal e zonas horárias globalmente estandardizadas, como o nosso hoje, é social e experiencialmente diferente de todas as eras pré-modernas. O mapa global, no qual não há privilégio para o lugar (uma projeção universal), é a contrapartida simbólica do relógio no respeitante ao "esvaziamento" do espaço. 
Isso implicou o dinamismo maciço que a modernidade introduz nos assuntos sociais humanos; a historicidade assume uma forma global com a criação de um "passado" padronizado e um "futuro" universalmente aplicável, uma data como o ano 2000 torna-se um marcador reconhecível para toda a humanidade; a descontextualização das instituições sociais - remoção das relações dos contextos locais e a sua rearticulação por meio de trechos indefinidos de espaço-tempo; e reflexividade institucional - "uso regularizado do conhecimento acerca das circunstâncias da vida social enquanto elemento constituinte implicado na sua organização e transformação" (GIDDENS, 1997).

A globalização, fenômeno tão debatido na pós-modernidade, tem influência no distanciamento entre espaço-tempo. Ela entrelaça eventos sociais e relações sociais a distância com as contextualidades locais. Isso implica relação dialética, na qual os eventos em um dos polos produzem muitas vezes ocorrências divergentes ou mesmo contrárias no outro polo. A media tem capital importância nesse processo:

Para Giddens (1997), os materiais impressos atravessam o espaço tão facilmente como o tempo porque podem ser distribuídos a muitos leitores mais ou menos simultaneamente. Segundo ele, calcula-se que, a um nível global, a quantidade de materiais impressos tenha duplicado a cada quinze anos desde Gutemberg.

A media, ainda segundo o autor, produz feito de colagem - forma uma justaposição de histórias e itens que nada têm em comum além do fato de serem "oportunos" e consequentes (página de jornal e programas de televisão em um mesmo jornal). Segundo traço, importante para tempos modernos, é a intromissão de acontecimentos distantes na consciência cotidiana local.

Qual é a natureza e a característica do discurso mediatizado? Segundo van Dijk (1997), é provável que não exista nenhuma outra prática discursiva, exceto a conversação cotidiana, que se pratica com tanta frequência e por tanta gente como são no segmento de notícias na imprensa e na televisão.

Sobre a organização das notícias em um jornal, ele afirma que os temas são organizados, normalmente, por meio de um esquema abstrato em categorias 
convencionais que especificam a função geral dos temas em um texto. Tal esquema chama-se "superestruturas". Os noticiários seguem um esquema hierárquico que consiste em uma série de categorias convencionais tais como: título, primeira página (que junto ao anterior formam o sumário), notícias em destaque, contexto, história (juntas formam a categoria de fundo), reações verbais e comentários.

Os meios de comunicação exercem papel muito importante nas estruturas sociais, tanto nas instituições privadas como nas estatais. Nas sociedades industrializadas, são a instituição de reprodução ideológica, talvez mais importante que o sistema educacional propriamente dito.

Mas o jornal não é só isso. Escolher esta matéria ou aquela é um processo ideológico. A maioria dos publicitários no mundo ocidental é branca, de classe média, pertence a grupos dominantes, e isso reflete na elaboração de notícias, contribuindo para a reprodução de consenso da ideologia profissional e social, que subjazem no processo de elaboração de notícias. No próximo tema, veremos como o racismo e o preconceito estão presentes na mídia.

\subsection{0 racismo na/da mídia}

Neste item, sairemos dos aspectos gerais da mídia e passaremos a caracterizar mídia e racismo, ou seja, presença das minorias étnicas na mídia - assunto mais específico para os objetivos da nossa pesquisa. Para tanto, abordaremos as propriedades das notícias sobre grupos étnicos minoritários - apresentação, frequência e tamanho, temas e estruturas temáticas, papéis desempenhados, significado local, estilo e perspectivas. Tomaremos como base o livro de van Dijk, Racismo y análisis crítico de los médios (1997). Vejamos o que diz esse autor.

A mídia geralmente publica assuntos referentes às instituições brancas - governo, polícia, parlamento, mas não assuntos sobre minorias étnicas. Estas fazem parte da classe trabalhadora, estão menos organizadas em instituições de poder e têm pouca influência política: as dimensões de raça e classe somadas produzem identidades sociais e, portanto, práticas sociais determinadas que refletem na es- 
colha da matéria a ser publicada pelos jornais. Quando publicam algo sobre essa minoria, fazem-no sobre aspectos negativos tais como: distúrbios, crimes etc.

A apresentação - propriedades visuais que influenciam na recepção - de notícias sobre grupos étnicos minoritários, em relação aos títulos, é maior que outras informações. Estas são publicadas em páginas internas, a menos que se trate de um crime, de violência ou distúrbio de grandes proposições.

Sobre o tema e a estrutura temática, o estudo sobre o conteúdo e sobre o significado pode desenvolver-se em nível local de palavras ou frases e em nível global de temas. Os temas expressam a informação mais importante do texto e formam uma estrutura temática de hierarquias que também está presente no sumário de um texto. Infelizmente, segundo o autor, todas as pesquisas que se referem à informação sobre as minorias étnicas na mídia não definem com precisão a ideia de tema. Geralmente, chamam de tema ou matérias - imigração, educação ou discriminação. Ao se falar sobre estrutura temática, está se falando em aspectos qualitativos. Muitos assuntos como imigração podem, geralmente, incluir outros, permitindo, assim, maior abstração e generalização. Exemplo: imigração - números que entram/saem da Inglaterra; controles governamentais; pessoas de cor: entrada na Inglaterra; etc. A partir de estudos realizados na Europa, há maior consenso em afirmar que as instituições consideram as minorias causadoras de problemas. As autoridades preferem descrevê-los como "causadores de dificuldade", usando expressão eufêmica.

Nos papéis desempenhados, quais são aqueles exercidos pelas minorias? Para os temas negativos dominantes, os protestos ou a delinquência, o papel dessa minoria está muito claro: são agentes ativos e responsáveis e não vítimas. A um nível específico de organização sintática, a distribuição de papéis tem sido investigada sistematicamente por Fowler (Apud FAIRCLOUGH, 2001) e outros. Suas investigações demonstram que a estrutura de ação das frases tal como expressa na ordem das palavras, as relações gramaticais (sujeito, objeto etc.), ativas e passivas, nas informações sobre distúrbios, os grupos minoritários desempenham um rol de agente-tema, particularmente em contextos negativos. 
Esse estudo sobre a distribuição de papéis tem várias causas cognitivas e estruturais: primeiro, como os grupos minoritários são mais dominados na Europa Ocidental, estão menos organizados e têm menos acesso aos meios de comunicação - coletivas de imprensa, notas na imprensa ou porta-vozes designados; segundo, os publicitários, por sua vez, são menos tendentes a buscar informações a grupos minoritários; terceiro, dizem que tais fontes não são objetivas e, por isso, gozam de menos credibilidade; isso se prova, segundo eles, pelas partículas de dúvida e de distância, assim como o emprego mais frequente de aspas para citar alguém que não tem permissão para falar; quarto, praticamente todos os jornalistas na Europa Ocidental pertencem à raça branca e não têm relação nem pessoal, nem profissional com as classes minoritárias.

A partir das observações de nível semântico, podemos concluir que os grupos étnicos ou raciais e as relações sociais em uma sociedade multiétnica são associados a problemas, conflitos, dificuldades, para não mencionar violência e ilegalidade.

\section{Análise de texto}

Antes de passarmos à análise de texto propriamente dita, temos de fazer algumas incursões teóricas na obra de Norman Fairclough, Discurso e mudança social (2001), sobre o que é discurso, e, paralelamente, a análise de texto. Para isso, utilizaremos os capítulos 3 e 6 e, como prática, o capítulo 8.

Segundo Fairclough (2001), o termo discurso implica considerar o uso da linguagem como prática social, e não como ato puramente individual ou reflexo de variáveis situacionais. E isso tem implicações: primeiro, é que o discurso é uma forma de ação - em que as pessoas agem sobre as outras no mundo - e de representação. Mas o discurso não apenas representa o mundo; é uma significação do próprio mundo. Segundo, é considerar a relação dialética entre discurso e estrutura social. O discurso é moldado e restringido pela estrutura social no sentido mais amplo e em todos os níveis. 
Quais são os efeitos constitutivos do texto? Segundo o autor citado, o discurso contribui para a construção de identidades sociais e de posições de sujeito para os sujeitos sociais e tipos do eu; contribui para construir as relações sociais entre as pessoas e ainda para a construção de sistemas de conhecimento e crença. Esses três elementos correspondem respectivamente às funções da linguagem: identidade - modos pelos quais as identidades sociais são estabelecidas no discurso; relacional - como as relações entre os participantes do discurso são representadas e negociadas; ideacional - modo pelo qual os textos significam o mundo e seus processos, entidades e relações; e, por último, a função textual - que informa como as informações são trazidas ao primeiro plano ou relegadas ao segundo.

A prática discursiva é constitutiva tanto de maneira convencional como criativa. No primeiro caso, apenas reproduz a sociedade; no segundo, pode transformá-la. Esse é o objetivo do autor, pois para ele, o discurso como prática política ideológica transforma as relações sociais de poder e as entidades coletivas quando existe relação de poder.

O que faz especificamente uma prática discursiva como discursiva? Parte da resposta está na linguagem com materialização no texto; a outra parte está na prática social, com todas as suas implicações ideológicas e políticas. O evento discursivo engloba tudo isso, pois é um produto histórico - ambiente econômico, político e institucional (origem do discurso). Leva em consideração a produção, a distribuição e o consumo de textos. Quanto ao primeiro, diz respeito à maneira como os textos são produzidos de maneira particular em contextos sociais específicos; o segundo refere-se ao consumo de textos em contextos sociais diversos, variando de acordo com sua natureza; o último explica como os textos são consumidos no mundo, podendo ser distribuídos de forma simples (conversação casual), ou complexa - texto jornalístico constrói leitores múltiplos.

Outro aspecto importantíssimo na obra de Fairclough (2001) é a concepção tridimensional do discurso. Veja-se o esquema: 


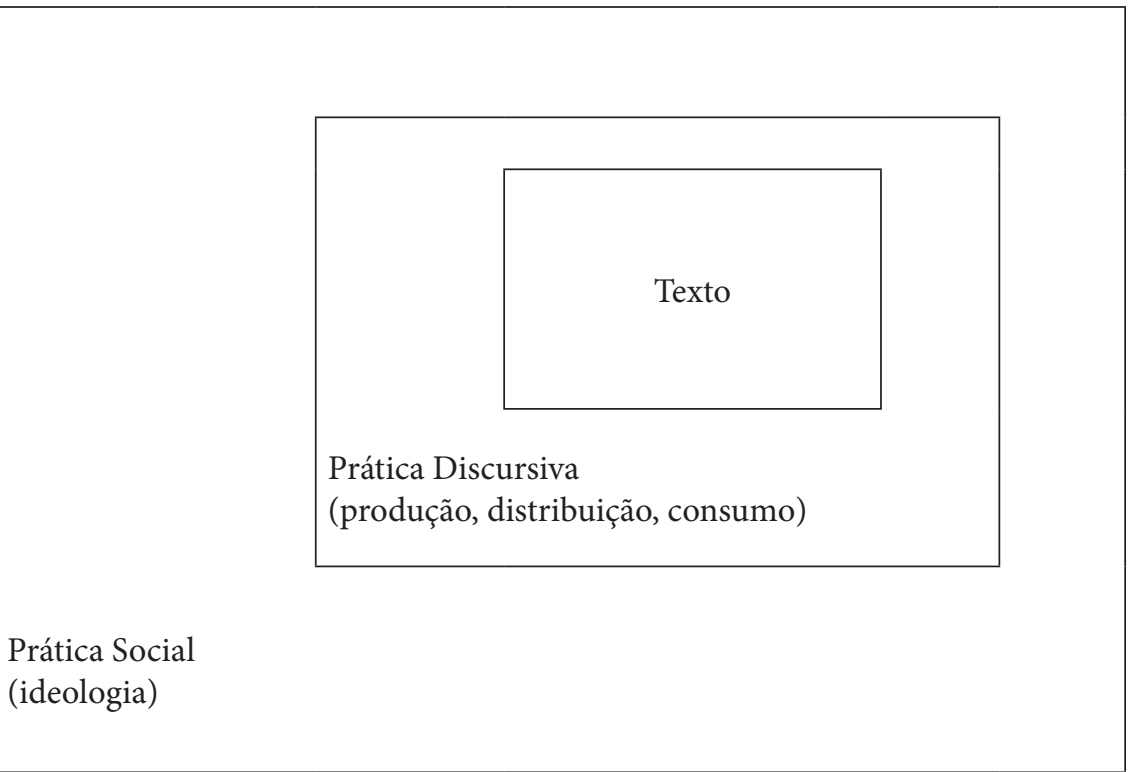

Ao apresentar tal esquema, o autor objetiva reunir três tradições analíticas que são indispensáveis para quem quiser fazer análise do discurso: a tradição da análise textual - detalhada na Linguística; a tradição macrossociológica de análise da prática social em relação às estruturas sociais; e a tradição interpretativa (microssociológica) de considerar a prática social como algo que as pessoas produzem ativamente e entendem com base em procedimentos de senso comum partilhado. A parte que trata da análise é denominada descrição; já as partes que tratam da análise, da prática discursiva e da análise da prática social, da qual o discurso faz parte, são denominadas de interpretação.

A produção e a interpretação de texto são um processo de níveis: processo inferior - analisa-se sequência de sons ou marcas gráficas em frases; processo superior - diz respeito ao sentido, à atribuição de sentidos às frases, a textos completos e a partes ou "episódios" de um texto que consistem de frases que podem ser analisadas coerentemente conectadas. A tudo isso têm de ser levados em consideração outros elementos como o fator de redução de ambivalência: contexto, contexto de situação, prática social etc.; a força dos enunciados que está ligada a seu componente acional, parte do seu sentido interpessoal, na ação social que realiza, que ato de fala realiza - dar ordens, perguntar, ameaçar, prometer etc. Nesse caso, antes que 
se passe a analisar o contexto de situação ou mesmo o contexto sequencial para analisar a força do enunciado, deve-se chegar a uma interpretação sobre qual é o contexto de situação, o que envolve pistas e recursos dos membros - mapa mental de ordem social: identidade social (etnia, idade, gênero). A coerência, que é a propriedade de interpretação. Um texto é considerado coerente quando faz sentido para o receptor, mesmo que não haja operadores lógicos. Ao se fazer interpretação textual, sujeita-se ao texto. E, por último, intertextualidade que, segundo o autor, é de maior importância para a Análise Crítica do Discurso - ACD, pois é a propriedade que têm os textos de serem cheios de fragmentos de outros textos. Pode ser delimitada explicitamente (intertextualidade manifesta - ocorrência explícita de outro(s) texto(s)), ou implicitamente (intertextualidade constitutiva - ou interdiscursividade - constituição heterogênea de texto por meio de elementos das ordens do discurso).

Outro conceito importante para análise de discurso é o de hegemonia. Em termos ideológicos, ela é o poder sobre a sociedade como um todo, de uma das classes economicamente definidas como fundamentais em aliança com outras forças sociais, atingindo equilíbrio temporário. Além disso, a prática discursiva na produção, na distribuição e no consumo, é uma faceta da luta hegemônica que contribui em graus variados para a reprodução ou a transformação não apenas da ordem de discurso existente, mas também das relações sociais assimétricas. Para Fairclough (2001), o conceito de hegemonia auxilia na análise tridimensional do discurso porque fornece tanto uma matriz - uma forma de analisar a prática social a que pertence o discurso em termos de relação de poder - como um modelo uma forma de analisar a própria prática discursiva como um modelo de luta hegemônica, que reproduz e reestrutura ou desafia as ordens de discurso existentes.

Como ocorrem as mudanças nos eventos, nas ordens de discurso e em nível societário? O autor afirma que, no primeiro caso, a mudança ocorre na problematização das convenções dos produtores ou intérpretes que podem ocorrer de várias maneiras: convenções na interação entre homens e mulheres, a partir da contradição de posições entre sujeitos genéricos tradicionais e as novas relações de gênero; na intertextualidade, a mudança textual implica transgressão. No segundo caso, ocorrem a partir das combinações discursivas - códigos e elementos de maneira 
nova em eventos discursivos novos - que mudam as ordens de discurso. À medida que essa mudança avança, naturaliza-se, tornando-se nova convenção emergente. No nível societário, a mudança ocorre na aparente democratização do discurso (perda de assimetria), personificação sintética (transformação de discurso privado em público).

No capítulo 6, intitulado "A análise textual: a construção da realidade social”, Fairclough (2001) nos apresenta os elementos da análise de texto que se relacionam com a função ideacional da linguagem e com os sentidos ideacionais, ou com a "construção da realidade social" e nos dá os passos para que se faça a ACD.

Em primeiro lugar, apresentaremos o texto com o qual iremos trabalhar, o contexto situacional, gênero discursivo e, em seguida, seguiremos as indicações de análise do autor. Os três últimos servirão como prova de que a prática do racismo circula, naturalmente, em veículo de comunicação. Como a ACD é uma disciplina interdisciplinar, para Fairclough (2001), a Análise de Discurso deve ser idealmente um empreendimento interdisciplinar. Segundo ele, essas facetas do discurso coincidem com os interesses de várias ciências sociais e humanistas, incluindo a Linguística, a Psicologia e a Psicologia Social, a Sociologia, a História e a Ciência Política.

Neste artigo, trabalhamos com textos da obra Bruxas, espíritos e outros bichos, de Edson Lopes Cardoso (1992), membro da Executiva Nacional do Movimento Negro Unificado - MNU, porque cremos que a Linguística, especificamente na área da $\mathrm{ACD}$, pode contribuir para enriquecer outras áreas, já que é bem mais instrumentada para tal intento.

Todos os textos, sob análise, foram publicados em 1988 com o advento dos cem anos da Abolição da Escravatura, momento em que houve muitos festejos e protestos. Na crônica, publicada em 19 de janeiro em A Tarde, no Caderno 2, p. 3, jornal de maior circulação no estado da Bahia, local de maior população negra no País, a autora, Vera Luedy, lamenta a perda da sua tão amada babá, Chica, ocorrida no dia 5 de janeiro. "Chica Bondade", Chiquinha, era uma mulher negra que dedicara "grande parte de sua existência à Família Luedy". 


\subsection{Descrição}

O primeiro texto é uma crônica, gênero literário, narrativo, que aborda aspectos do cotidiano, veiculado em jornal; os dois últimos são jornalísticos (trechos de jornal). Todos os três têm uma característica única: os órgãos de imprensa colocam seus pontos de vista e assim também contribuem para formar opinião pública favorável a seus objetivos. Vejamos o texto:

\section{Chica Bondade}

Grande parte de sua existência foi dedicada a nossa família. Muitas vezes a surpreendi conversando com os meus vestidos superengomados, exigente muito que minha mãe era, e enquanto passava a roupa ia dizendo: 'Você tem que ficar bem bonito pra minha fia ficá linda, não quero uma dobrinha. Minha fia vai passear e todo mundo vai olhar pra ela'. As 'fiảde Milucha teriam de andar impecáveis.

Certo dia, eu ainda era uma criança, perguntei por que ela ficava tanto tempo ajoelhada, rezando. 'Chiquinha, seus joelhos vão ferir de tanto você rezar, pra que ficar nesta posição?'

Imediatamente ela respondeu: 'Minha fia, é pedindo a Santo Antônio pra te livrar de uma paixão quando ficá mocinha. Paixão é a pior coisa deste mundo?

Não conseguiu, com suas preces, livrar-me da paixão, mas estou certa que foram suas orações de joelho que colocaram no meu caminho o meu 'Santo Antônio' em carne e osso.

Minha preta querida, seu legado de carinho, dedicação, fidelidade e amor não se pode medir.

Você partiu no dia 5 de janeiro, descansou desta batalha, deixando-me a certeza que não se fazem mais babás iguais a você. Resta o consolo de que você vai encontrar seu patrão adorado e meu Alexandre, que você tão bem amou. Vai estar livre dos telefonemas que você odiava e nunca aprendia a atender corretamente como mamãe ensinava: como existiam dois Alfeu lá em casa, vinha sempre a célebre pergunta: 'Fio ou pai'? Livre de substituir as copeiras nas folgas ou na falta delas, o que mais você detestava e só desabafava comigo, pois o que gostava mesmo e o fazia como ninguém era cuidar das roupas e mascar fumo, escondida no quintal, e não havia meio de entrar em sua cabecinha grisalha a maneira certa de servir mesa à francesa, como mamãe queria. 
Conservo sua imagem de cão-de-guarda, tomando conta do silêncio nas portas dos quartos dos meus pais, e quando chegava, para as temporadas políticas, o tio Simões, você vigiava de dedo na boca e psiu sempre as portas do corredor, para que nada perturbasse o repouso dele. 'O doutor Simões chegou, minha fia, não faça barulho senão ele briga com você. Sabe como ela é pro lado desse velho. Nem a mosca pode voar e ela qué calar a boca até dos passarinhos pra não acordar ele'.

Na sua santa ignorância você ensinou a educar meu lado mais simples e puro, e me deixou a grata recordação de ter sido tão bem amada na infância.

Sua presença será sempre uma constante em minha vida e fico feliz, Chiquinha, porque transmiti a admiração e o amor que tive por você aos meus filhos rapazes. Um deles já perguntou onde você está enterrada: 'Quero levar flores pra Chica, mãe'.

Chica Bondade tão bem sabia identificar-se com nossas tristezas e sobretudo com nossas alegrias, e conseguir dar-se por inteiro (o que é tão difícil) nas mínimas coisas que fazia.

Fui melhor aquinhoada que os meus irmãos mais velhos, que tiveram governanta estrangeira e com elas aprenderam a falar francês e alemão (Mmle. Giroud) e fico devendo aos meus filhos uma figura igual a Chica. (LUEDY, 1988, p. 3).

Segundo Faiclough (2001), quando se faz uma análise de texto relaciona-se este com a função ideacional da linguagem e com os sentidos ideacionais - ou com a "construção da realidade social". Os tópicos analíticos levantados pelo autor são: conectivos e argumentação, transitividade e tema, significação das palavras, criação de palavras e metáfora e análise.

Vejamos cada um desses, com especificação teórica e prática.

\subsection{Conectivos e argumentação}

No nosso texto, os operadores lógicos como: referência - anterior (ela, delas); posterior (sua, a (complemento); coesão lexical - sinonímia (Chiquinha, preta querida, Chica Bondade, Chica, Mãe); elipse - de sujeito (passava, perguntei, con- 
seguiu), de verbo (... sabia identificar-se com as nossas tristezas e sobretudo (sabia identificar-se) com nossas alegrias,...) etc., formando uma rede de relações que contribuem para o que se chama, em linguística textual, de tessitura (textualidade). Mas não há elementos coesivos mais ideologicamente construídos do que os dois que se referem à Milucha (Mãe de Vera Luedy) - ela, ele - e ao tio Simões.

Vejamos trechos pelos quais a identidade dos dois é construída: Milucha “[...] exigente muito que minha mãe era [...]”, “[...] nunca aprendia a atender corretamente como mamãe ensinava [...]”, “[...], e não havia meio de entrar em sua cabecinha grisalha a maneira certa de servir mesa à francesa, como mamãe queria”. Ao tio Simões - “[...], e quando chegava, para as temporadas políticas, o Tio Simões [...]", "O doutor Simões chegou, minha fia, não faça barulho senão ele briga com você”. Todos esses trechos passam-nos a identidade do branco, patrão, mandão.

\subsection{Transitividade e tema}

"A escolha do tipo de processo para significar um processo real pode ter significação cultural, política ou ideológica" (FAIRCLOUGH, 2001). Segundo este autor, ao se fazer análise dos tipos de transitividade, temos de levar em consideração os processos que são codificados em orações e com os tipos de participantes (elementos de orações). Podem ser divididos em dois principais processos: os relacionais em que o verbo marca uma relação (ser, tornar-se) entre os participantes, e de ação, em que um agente age em direção a um objetivo. Já tema significa uma dimensão textual da gramática da oração dedicada aos modos pelos quais os elementos da oração são posicionados de acordo com sua proeminência informacional. Rema é a parte final. No texto sob análise, quase todas as orações são de ação dirigida (um agente age em direção a um objetivo).

Passemos à análise.

Os processos relacionais são poucos dentro do texto; em contrapartida, os processos de ação constituem quase todo o texto. Estes são construídos por meio de verbos que se caracterizam de diferentes maneiras na relação do ser consigo 
mesmo ou em relação ao mundo referencial. Os verbos relacionais (ser, ficar), ou não nocionais, possuem natureza gramatical, integram um predicado nominal. Os verbos nocionais possuem natureza dinâmica, e podem ser divididos em intransitivos (ação não dirigida), em que a ação fica restrita ao próprio ser, caracterizando um sujeito isolado; transitivos (ações dirigidas), em que já se fala de um sujeito que se relaciona com outro ser - o objeto - exprimindo dinamismo da vida, em todos os níveis de relacionamento. Esses são os mais expressivos para descrever o texto, já que a presença é marcante. Ao se levantar a transitividade e tema/rema do texto, ficam claras as relações de identidade.

Iremos levantar as ações dirigidas de Vera Luedy e, em seguida, as de Chica Bondade. Saltarão aos olhos as diferenças sociais e, por consequência, as diferenças de identidade. Empregaremos também frases que fazem parte do mundo da produtora e frases que fazem parte do mundo de Chica Bondade. Usaremos um quadro para que as diferenças fiquem mais marcantes.

Ao analisar o quadro, ficam muito claras as diferenças de natureza verbal (semântica) e de transitividade - o que implica, segundo o que mencionamos antes, significação cultural, política ou ideológica, acentuando as diferenças identitárias. Chica Bondade, no seu mundo, referencial, conversa com vestidos, passa roupa, descansa da batalha, "do outro lado", vai encontrar O Patrão (vai continuar sendo escrava), substituía outros empregados (não tinha folga), só cuidava de roupas, mascava fumo (escondida no quintal, reprimida), não consegue aprender a servir à francesa, toma conta do silêncio das portas (cão-de-guarda), identificava-se com as alegrias e tristezas dos outros (mas não tinha as suas), dava-se por inteiro.

Em contrapartida, vejam-se as transitividades da tabela para Vera Luedy: "a surpreendi conversando com meus vestidos, conservo sua imagem, transmiti a admiração e o amor, meus irmãos mais velhos tiveram babá estrangeira, e aprenderam a falar francês e alemão" (colocando como desvantagem, disfarçando esnobismo).

"As escolhas mencionadas do tema são freqüentemente interessantes pelo que elas mostram não apenas sobre as estratégias retóricas” (FAIRCLOGH, 2001). 


\section{Quadro 1}

\begin{tabular}{|c|c|}
\hline \multicolumn{2}{|c|}{ PROCESSO DE AÇÃO } \\
\hline Vera Luedy & Chica Bondade \\
\hline $\begin{array}{l}\text {... a surpreendi conversando com os meus } \\
\text { vestidos ... } \\
\text {... perguntei por que ela ficava tanto tempo } \\
\text { ajoelhada, rezando ... } \\
\text {... suas orações de joelho colocaram no meu } \\
\text { caminho o meu "Santo Antônio"... } \\
\text { Minha preta querida, seu legado de amor e } \\
\text { carinho ... não se pode medir. } \\
\text {... conservo sua imagem de cão-de-guarda ... } \\
\text { Na sua santa ignorância você ensinou a edu- } \\
\text { car meu lado mais simples e puro, ... e me dei- } \\
\text { xou a grata recordação de ter sido tão bem } \\
\text { amada na infância. } \\
\text {... transmiti a admiração e o amor que tive } \\
\text { por você aos meus filhos ... } \\
\text { um deles já me perguntou onde você está en- } \\
\text { terrada... quero levar flores ... } \\
\text {... es méus irmães mais velhos, que tiveram } \\
\text { babá estrangeira, ... aprenderam a falar fran- } \\
\text { cês e alemão } \\
\text { fico devendo aos meus filhos uma figura igual } \\
\text { a Chica. }\end{array}$ & $\begin{array}{l}\text {... conversando com os meus vestidos ... } \\
\text {... enquanto passava a roupa ... } \\
\text {... não quero uma dobrinha. } \\
\text {..., é pedindo (para pedir) a Santo Antônio } \\
\text { pra te livrar ... } \\
\text { Não conseguiu livrar-me da paixão, ... } \\
\text {... seu legado de carinho ... não se pode medir. } \\
\text {... descansou da batalha, ... } \\
\text {... deixou a certeza que não se fazem babás } \\
\text { iguais a você. } \\
\text {... você vai encontrar seu patrão adorado e } \\
\text { meu Alexandre que você tanto amou. } \\
\text {... livre dos telefonemas que você odiava ... } \\
\text {... nunca aprendia a atender corretamente ... } \\
\text {... o que você mais detestava (substituir outras } \\
\text { empregadas) ... } \\
\text {... gostava de cuidar das roupas ... } \\
\text {... mascar fumo ... } \\
\text {... não havia meio de entrar em sua cabeci- } \\
\text { nha grisalha a maneira certa de servir mesa } \\
\text { a francesa, ... } \\
\text {... tomando conta do silêncio das portas dos } \\
\text { quartos ... (duas vezes no texto) } \\
\text {... sabia identificar-se com nossas tristezas (e } \\
\text { identificar-se com nossas alegrias), ... } \\
\text {... e conseguir dar-se por inteiro ... } \\
\text {.. mínimas coisas que fazia. }\end{array}$ \\
\hline
\end{tabular}


No início do texto, temos um sujeito paciente (em voz passiva), em que o agente ainda não está especificado na linearidade imediata e, sim, inferido no título, e em seguida cataforicamente encontrando: “Chiquinha” (2 parágrafo). Veja-se a forma de se colocar a expressão "Grande parte de sua existência” como tema. Significa que um ser alienou-se a vida inteira em prol dos outros. Tudo isso intensificado por outras expressões adverbiais como "muitas vezes" (tema), "tanto tempo" e "sempre"; e verbos como "conversando" "tomando conta" (ação contínua), "vigiava", "falava", "fazia" (ação iniciada no passado, teve duração e terminou no próprio passado).

Vejam-se outros advérbios como tema: "certo dia”, "imediatamente", "na sua santa ignorância”.

\subsection{Significação das palavras}

Quanto à significação das palavras, diz Fairclough (2001, p. 230):

Os significados das palavras e a lexicalização de significados são questões que são variáveis socialmente contestadas, e facetas de processos sociais e culturais mais amplos [...] e o sucesso em obter aceitação para significados particulares de palavras, e para uma estruturação particular do seu significado potencial é, sem dúvida, interpretável como uma forma de adquirir hegemonia.

Como confirmação de tal teoria, veja-se o quadro abaixo em que comparamos as palavras (ou sintagmas) das identidades levantadas pelo texto, palavras que fazem parte do mundo de Chica e de Vera Luedy: 


\section{Quadro 2}

\begin{tabular}{|c|c|}
\hline \multicolumn{2}{|c|}{ DIFERENÇAS DE IDENTIDADE PELO LÉXICO } \\
\hline Vera Luedy & Chica Bondade \\
\hline - Família & - $\quad \varnothing$ \\
\hline - Vestidos superengomados & - $\varnothing$ \\
\hline$\bullet \quad \varnothing$ & - $\quad$ Passadeira \\
\hline - $\quad$ Passeio & - $\varnothing$ \\
\hline - Cobicada & - $\varnothing$ \\
\hline - Impecável & - $\varnothing$ \\
\hline - Infância & - $\varnothing$ \\
\hline - $\varnothing$ & - $\quad$ Reza \\
\hline - $\quad$ Paixão & $\cdot \varnothing$ \\
\hline - Casamento & $\cdot \varnothing$ \\
\hline - Branca & - $\quad$ Preta \\
\hline - $\varnothing$ & - $\quad$ Dedicação \\
\hline - $\varnothing$ & - $\quad$ Fidelidade \\
\hline - Amor & - Amor \\
\hline - $\varnothing$ & - Babá \\
\hline - Hábil & $\begin{array}{l}\text { - Inábil (para atender ao telefonema } \\
\text { e servir à francesa) }\end{array}$ \\
\hline$\cdot \varnothing$ & - Sem folga \\
\hline - $\varnothing$ & - $\quad$ Fumo (substantivo) \\
\hline$\cdot \varnothing$ & • “Cão-de-Guarda” \\
\hline • $\varnothing$ & - Ignorante \\
\hline - Lado simples educado & - Educadora \\
\hline - $\quad$ Amada na infância & • $\varnothing$ \\
\hline - $\quad$ Filhos & - $\varnothing$ \\
\hline - $\varnothing$ & - Doacão \\
\hline - $\quad$ Bem aquinhoada & - $\varnothing$ \\
\hline
\end{tabular}

Não precisamos recorrer a explicações outras, as próprias palavras o fazem. 


\subsection{Análise}

Por meio da descrição que fizemos, tendo como base Fairclough (2001) transitividade e tema, coesão e coerência, significado das palavras - chegamos à conclusão de que a imagem de "Chica Bondade" passada pela crônica é de um ser alienado, em altíssimo grau. Não teve vida própria, dedicou-se a vida inteira aos outros como identidade de escrava.

Veja-se que a autora a coloca como um ser que vive a identidade dos outros e que tem práticas que não são de sua própria identidade - prática religiosa europeia - e como ser bestial que conversa com objetos, a tudo isso soma-se ao tratamento dispensado à Chiquinha: "cão-de-guarda", "preta querida" ("preta" é expressão não politicamente correta, hoje emprega-se "negro" ou "negra") e burra.

O texto deixa claros os mecanismos de dominação da mulher escravizada, sem passado, sem futuro, restando-lhe apenas o presente como realidade crua. Chiquinha não tem passado (veja-se o último quadro comparativo) - sem mãe, pai, filhos. A crônica não faz nenhuma referência a isso. De onde Chiquinha veio?

Vera Luedy lamenta muito a morte de sua "mãe preta", dizendo que não se fazem mais babás como antigamente: não reclamam direitos trabalhistas, não têm dia de folga, férias. O que a consola é que Chiquinha irá encontrar "do outro lado" o seu Patrão adorado - escravidão na terra, escravidão no "céu”: negra sempre servindo, patrão sempre mandando. Lá ela aprenderá a servir à francesa, atender a telefonemas e a mascar fumo, sem ser perturbada.

Lamentar a morte de Chica Bondade é uma simbologia de "[...] morte de mães pretas apropriadas para famílias brancas como a sua" (CARDOSO, 1992). "Fico devendo a meus filhos uma figura como Chiquinha".

Pela análise linguística feita, ficou evidenciado que, dada a pequena dimensão do texto, a quantidade de estereótipos racistas é muito grande.

Podemos finalizar com Cardoso (1992) quando afirma que a crônica de Vera Luedy acumula antigas manifestações do imaginário racista: inferioridade 
intelectual do negro ("não havia meio de entrar em sua cabecinha"), perpetuação, por incapacidade congênita, da condição servil, exploração do campo afetivo ("o amor que tive por você ...") etc.

Vejam-se outros exemplos de racismo publicados em 13/05/1988, data de aniversário da Abolição da Escravatura. O último exemplo é interessante porque mostra uma construção de identidade do negro por quem faz notícia (em negrito estão os preconceitos).

O cirurgião dentista, católico, dr. Urbano de Assis Xavier, começou a sofrer os sintomas de mediunidade, com desmaios semelhantes aos da epilepsia. O espírito de um preto velho, que dava o nome de Pai Jacó, manifestouse, incorporando no próprio dentista, aconselhando-o a procurar, em Matão, o farmacêutico (Caibar Schutel, de origem alemã e diretor de um jornal e de uma revista espíritas).

[...]

Caibar Schutel resolveu fazer um teste de mediunidade, mas disse: 'Não está me agradando essa história de preto velho'. Ao terminar, Caibar disse ao dr. Urbano: - Não gosto de negros e índios, mas o seu Pai Jacó encheu-me as medidas, revelando um conhecimento doutrinário que me assombrou. Pai Jacó me explicou ter sido médico holandês em encarnação anterior, mas agora viera como negro, para aprender a ter humildade (C. E. M, 2011)

Atrás da pele escura, do cabelo crespo e dos dentes brancos há corações grandes e abertos, inteligências raras, talentos artísticos de rara criatividade como só um ser humano pode apresentar.

[...] produto nosso, uma das melhores e mais resistentes raças brasileiras. Com boa moradia, com boa remuneração, bem alimentado e com salário compatível, o negro dá excelente produção e é saudável, causando pouca correria aos postos de saúde. (ARNHOLD, 1988, p. 22). 


\section{Considerações finais}

Nosso objetivo inicial foi determinar a construção da identidade das minorias étnicas - notadamente a do negro - na mídia. Depois da pesquisa bibliográfica e da pesquisa de material impresso em jornais, chegamos às seguintes conclusões:

Os meios de comunicação exercem papel preponderante nas sociedades, influenciando instituições e vidas privadas. Em termos ideológicos, são mais influenciadores do que a própria escola.

Ao se publicarem as matérias, há todo um crivo ideológico. Os artigos de jornal são produzidos de maneira particular em contextos sociais específicos e de maneira coletiva, muitos deles, segundo Fairclough (2001), são produzidos coletivamente, mas só um membro assina. Nisso está implícita a presença da censura.

A maioria dos produtores de texto na mídia faz parte de cultura - pessoais, políticas e ideológicas - diferentes das minorias étnicas que são notícia de jornal.

Sendo assim, os assuntos referentes às comunidades brancas são mais publicados. Essas comunidades possuem maior poder econômico, estão política e ideologicamente bem constituídas, e seus relatos são confiáveis, porque gozam de confiança prévia.

Em contrapartida, as minorias étnicas pertencem à classe trabalhadora. Somando a isso raça e classe social, produzem identidades sociais determinadas que refletem na matéria a ser publicada. Essas matérias abordam, geralmente, temas como: violência, tráfico de drogas, imigração, racismo em páginas internas, a não ser que o crime tenha sido de grandes proporções para receber manchete de capa.

Os quatro textos apresentados refletem o preconceito de maneiras distintas, pois não são notícias de distúrbios de minorias étnicas. O que se deve ressaltar 
é que foram publicadas no Centenário da Abolição da Escravatura. O primeiro, analisado como um todo, chamaríanos de "ingênuo racismo", pois o preconceito está tão arraigado de forma subliminar na autora da crônica que nem se apercebe racista. $\mathrm{O}$ três últimos não fogem à regra, com exceção do primeiro, em que o preconceito fica explícito.

As expressões empregadas nos textos como: "preta querida", "santa ignorância", cão-de-guarda; "eu não gosto nem de negro, nem de índio, mas o seu preto velho me ensinou muitas coisa doutrinárias porque já tinha sido médico holandês na outra reencarnação, por isso veio como negro para pagar os pecados"; "produto", "o negro dá excelente produção" etc, perpetuam a imagem do negro, ideologicamente construída.

Para finalizar, façamos nossas as palavras de Cardoso (1992) quando assevera que a crônica de Vera Luedy acumula antigas manifestações do imaginário racista: inferioridade intelectual do negro, perpetuação, por incapacidade congênita, de condição servil, animalização, transposição da relação de dominação e exploração para o campo afetivo.

Segundo o autor, o que se postula é a igualdade, e não a marcação da diferença. Alguém ser negro ou branco, homossexual ou heterossexual, brasileiro ou alemão etc., é uma questão retórica, ideologicamente implantada.

\section{Racism and media}

\section{Abstract}

National cultures are composed not only of cultural institutions, but, also, from symbols and representations, and the speech is the senses construction/reconstruction/maintenance instrument that influence upon and organize both our actions as the conception that we have from ourselves. In this, the media speech exert preponderant influence in conscience formation and, mainly, in identities. But what is the relation between media and ideology? This paper's objective is to present the relation between mediatic speech, through published texts analysis, and ideology, notable about ethnic minoritys, the brasilian black. To answer this 
questioning, we run over through teoric pretext and the Critic Speech Analysis critic methodology, Fairclough (2001), and, interdisplinarly to Giddens (1997), Hall (2000), Thompson (2000), Eagleton (1997) and van Dijk (1997). After the corpus analysis, we came to the conclusion that, in news publishing, there is a whole ideologic sieve. The majority of texts producers, in the media, are part of cultures - political and ideological - diferent from the ones belonging to the ethnic minoritys. Our media, when following the perverse paradigm, gather old racist imaginary manifestations: the black intelectual inferiority, perpetration, through congenit incapacity, of servile condition, animalization, supremacy relation transposition.

Keywords: Linguistics. Critical Discourse. Analysis. Media. Racism.

\section{Referências}

ARNHOLD, Nelci T. Homenagem ao irmão negro. A Notícia, 13 maio 1988, p. 22.

BRASIL. Ministério de Trabalho e Emprego. Brasil, gênero e raça. Brasília, 1998.

CARDOSO, Edson Lopes. Bruxas, espíritos e outros bichos. Belo Horizonte: Mazza Edições, 1992.

COMUNHÃO ESPÍRITA DE MARÍLIA (C.E.M), 2011. Disponível em: <http:// comunhaoespiritademarilia.blogspot.com>, acessado em 1 nov. 2011. 17h10.

EAGLETON, Terry. Ideologia. São Paulo: Unesp, 1997.

FAIRCLOUGH, Norman. Discurso e mudança social. Brasília: UnB, 2001.

GIDDENS, Anthony. Modernidade e identidade pessoal. Oeiras: Celta, 1997. . Mundo em descontrole: o que a globalização está fazendo de nós. Rio de Janeiro: Record, 2001.

HALL, Stuart. Identidade cultural na pós-modernidade. Rio de Janeiro: DP\&A, 2000 .

HALL, Stuart; WOODWARD, Kathryn. Identidade e diferença: as perspectivas dos estudos culturais. Petrópolis: Vozes, 2000. 
82 Univ. Hum., Brasília, v. 8, n. 1, p. 53-82, jan./jun. 2011
Harrison da Rocha

Isto É. São Paulo: Editora Três, 4 jul. 2001.

LUEDY, Vera. Chica Bondade. Salvador: A Tarde, no Caderno 2, p. 3, 1988.

THOMPSON, John B. Ideologia e cultura moderna: teoria social crítica na era dos meios de comunicação de massa. Petrópolis: Vozes, 2000.

VAN DIJK, Teun A. Racismo y análises crítico de los medios. Barcelona: Paidós, 1997.

THOMPSON, John B. Ideologia e cultura moderna: teoria social crítica na era dos meios de comunicação de massa. Petrópolis: Vozes, 2000.

VAN DIJK, Teun A. Racismo y análises crítico de los medios. Barcelona: Paidós, 1997. 